\title{
Characteristics of patients with myocardial
} infarction with nonobstructive coronary arteries
(MINOCA) from the ARIAM-SEMICYUC registry:
development of a score for predicting MINOCA

This article was published in the following Dove Medical Press journal: Vascular Health and Risk Management

\author{
Daniel Ballesteros-Ortega' \\ Oscar Martínez-González' \\ Rafael Blancas \\ Gómez-Casero' \\ Manuel Quintana-Díaz ${ }^{2}$ \\ Eva de Miguel-Balsa ${ }^{3}$ \\ Carmen Martín-Parra' \\ Blanca López-Matamala' \\ Miriam Chana-García' \\ $M$ Ángeles \\ Alonso-Fernández' \\ Madián Manso-Álvarez' \\ On behalf of the ARIAM- \\ SEMICYUC Group \\ 'Critical Care Department, Hospital \\ Universitario del Tajo, CP 28300, \\ Aranjuez, Spain; ${ }^{2}$ Critical Care \\ Department, Hospital Universitario \\ La Paz, 28046 Madrid, Spain; ${ }^{3}$ Critical \\ Care Department, Hospital General \\ Universitario de Elche, 03203 Elche, \\ Alicante, Spain
}

Correspondence: Rafael Blancas Gómez-Casero

Unidad de Cuidados Intensivos, Hospital Universitario del Tajo, Avenida Amazonas Central s/n, Aranjuez 28300, Spain

Tel +34 6I 6078296

$\mathrm{Fax}+34918014180$

Email rafael.blancas@salud.madrid.org
Background: Acute myocardial infarction (AMI) with no evidence of relevant stenosis of the coronary artery, known as myocardial infarction (MI) with nonobstructive coronary arteries (MINOCA), has a prevalence of up to $14 \%$. The various causes of MINOCA lead to damage of the myocardium, and there are marked differences in diagnoses, prognoses, and treatments. Although the number of patients affected is considerable owing to the high prevalence of acute coronary syndrome (ACS), the causes of MINOCA have received little attention with the result that some patients may not receive appropriate treatment. Awareness of this disease among clinicians has started only to improve since the beginning of the current century. The aim of this study was to develop a score that enables patients with MINOCA to be distinguished from patients with MI with coronary artery disease (MI-CAD) and thus to facilitate appropriate diagnosis and therapy. Patients and methods: A multicenter observational cohort study was designed. All patients aged $\geq 18$ years from the ARIAM-SEMICYUC (Analysis of Delay in AMI-Spanish Society of Intensive Care Medicine and Coronary Unit) registry, diagnosed with AMI, and admitted to critical care units or coronary care units (CCUs) were included. Patients were classified into two groups: MINOCA, comprising patients with no significant lesions on angiography, and MI-CAD, comprising patients with lesions of the coronary artery tree.

Results: A score based on standard variables to assess the probability of MINOCA on admission was designed, showing a maximum value corresponding to a $40 \%$ probability of MINOCA. The discriminative power of the model was 0.756 ( $P$-value for the Hosmer-Lemeshow test was $>0.05$ ). At 30-day follow-up, the mortality rate was higher for MI-CAD patients.

Conclusion: Patients with MINOCA constitute a population that differs from other patients with AMI. Their differential characteristics require a certain diagnostic effort to align therapy with the disease causing the ischemic event. This score could prove useful in establishing additional diagnostic procedures.

Keywords: MINOCA, acute myocardial infarction, nonobstructive coronary disease, coronary syndrome, score

\section{Introduction}

Coronary heart disease is responsible for one-third of deaths in patients aged more than 35 years in developed countries. ${ }^{1}$ In Europe, cardiovascular diseases cause approximately 4 million deaths annually, mainly owing to coronary heart disease. The disease generates costs of around $€ 196,000$ million per year, ie, $54 \%$ of all health care spending. ${ }^{2}$ 
The European Society of Cardiology defines myocardial infarction (MI) as an alteration of markers of myocardial damage, mainly cardiac troponin (cTn), together with other clinical, electrocardiographic, and imaging data compatible with myocardial ischemia, although this definition is constantly changing. ${ }^{3}$

Acute myocardial infarction (AMI) with no evidence of relevant stenosis of the coronary artery is known as MI with nonobstructive coronary arteries (MINOCA). Its prevalence ranges from $1 \%$ to $14 \%$ with a mean of $6 \% ., 4$ The various causes of MINOCA lead to damage of the myocardium, and there are marked differences in diagnoses, prognoses, and treatments. Although the number of patients affected is considerable owing to the high prevalence of acute coronary syndrome (ACS), the causes of MINOCA have received little attention with the result that some patients may not receive appropriate treatment. Awareness of this disease among clinicians has started only to improve since the beginning of the current century, when the results of the first studies were published.

The causes of MINOCA are extremely varied. It can be classed as disease affecting the epicardial arteries and disease affecting the microcirculation. Other causes that do not directly involve coronary circulation include myocarditis, various prothrombotic diseases, and diseases preventing successful functioning of the heart. ${ }^{6}$ Since affected patients are not candidates for coronary revascularization, other therapeutic strategies are needed to improve health and quality of life.

Given the heterogeneous nature of the causes of MINOCA, prognostic studies are of limited value and may be influenced by the etiology and by the degree of damage associated with AMI. In any case, the disease is associated with greater mortality and risk of cardiovascular disease than in the general population, in both the short term and in the medium term. ${ }^{4,5}$

Patients with MINOCA differ clinically from all other patients with AMI. They are more frequently younger, and the disease affects both sexes equally, unlike MI with coronary artery disease (MI-CAD). Patients with MINOCA tend to have fewer cardiovascular risk factors, and their serum markers of myocardial damage peak at lower levels., ${ }^{4,5,7-11}$

In Spain, the Spanish Society of Intensive Care Medicine and Coronary Unit (SEMICYUC) keeps a registry of acute coronary heart disease, the ARIAM (Analysis of Delay in AMI) registry, which has been kept running without interruption since $1994 .{ }^{12}$ The registry comprises clinical, diagnostic, and analytical data as well as prognostic tools, which form the basis of the present study.

Our aim was to develop a score that allows us to distinguish between patients with MINOCA and other patients with coronary disease on admission to hospital to reach a diagnosis and apply appropriate therapy. The secondary objective was to describe the characteristics of patients with MINOCA and their clinical course during admission and in the short term (30 days).

\section{Patients and methods}

We performed a multicenter observational cohort study involving 69 hospitals in Spain and Andorra. Patients from the ARIAM-SEMICYUC registry were included prospectively and analyzed retrospectively. The registry includes all patients who were admitted to the intensive care unit (ICU) and coronary care unit (CCU) with a diagnosis of ACS.

The study included all patients aged $\geq 18$ years and diagnosed with AMI within the previous 48 hours. The criteria for AMI and for the diagnosis of MINOCA were established according to those of the European Society of Cardiology in force. ${ }^{13}$ Patients that were not diagnosed with having AMI, minors with a personal history of coronary obstructive pathology, and those who did not undergo diagnostic coronary angiography during admission were excluded from the study.

We classified patients diagnosed with AMI into two groups: MINOCA, comprising patients with no previous diagnosis of coronary heart disease and no significant lesions (ie, no coronary artery stenosis $\geq 50 \%$ ) on the angiogram at admission, and MI-CAD, comprising patients with previously known lesions of the coronary artery tree at admission or coronary obstructive disease on the coronary angiogram taken during admission and/or the need for coronary angioplasty.

The study period was from January 2010 to March 2015. Patients were followed for 30 days after discharge from the ICU or CCU.

The ARIAM-SEMICYUC registry comprises hundreds of variables adjusted to the recommendations of national guidelines and European guidelines (the Cardiology Audit and Registration Data Standards [CARDS] and European Data Standards for Clinical Cardiology Practice), the manuals of which can be accessed from the registry web page. ${ }^{14,15}$ The variables selected for the study were those that could be used to identify the onset of MINOCA, according to previously published studies.

\section{Statistical analyses}

Categorical variables were expressed as absolute numbers and percentages. The chi-squared test was used to identify differences between the MINOCA and MI-CAD groups. Continuous variables are expressed as median (IQR). The Student's $t$-test was used to identify significant differences. Non-normal continuous variables were log transformed before the test was applied. 
Actual survival was evaluated on censored data by the Kaplan-Meier (KM) function estimator. Cox proportional hazards regression models were used for multivariate analyses and to build a nomogram. The predictors analyzed initially included all variables that were statistically significant in bivariate analysis; nevertheless, to develop the final model, a backward step-down selection method was performed. The nomogram was created; meanwhile, the reduced model with only significant variables was included. Internal validation of nomogram was performed by discrimination and calibration analysis. For that aim, Harrell's concordance index (c-index) was used for quantifying the nomogram accuracy and, similarly, calibration plots were presented to further validate the nomogram. Calibration was assessed by grouping patients with respect to their nomogram-predicted probabilities and comparing the mean of the observed KM estimate of mortality at 30 days. The regression model was validated by analyzing the discriminative power of the model using the $\mathrm{C}$-statistic (area under the receiver operating characteristic [ROC] curve) and the Hosmer-Lemeshow test.
The software used for the statistical analyses was STATA v. $12^{\circ}$ (StataCorp LP, College Station, TX, USA).

\section{Ethics}

The study was approved by SEMICYUC for the use of the ARIAM-SEMICYUC registry. The rules for appropriate use of the registry were followed. The registry data that were released for the research were anonymized from aggregated public data. The ARIAM-SEMICYUC adheres to Spanish legislation on observational post-authorization studies for medicines for human use and the Spanish data protection law. Local clinical research ethics committee did not require patients to give their informed consent.

\section{Results \\ Characteristics of patients with MINOCA in the ARIAM-SEMICYUC registry}

During the study period, a total of 12,899 patients with AMI were included in the ARIAM-SEMICYUC project. Of these, 9,993 underwent coronary angiography; 9,241 were classed as

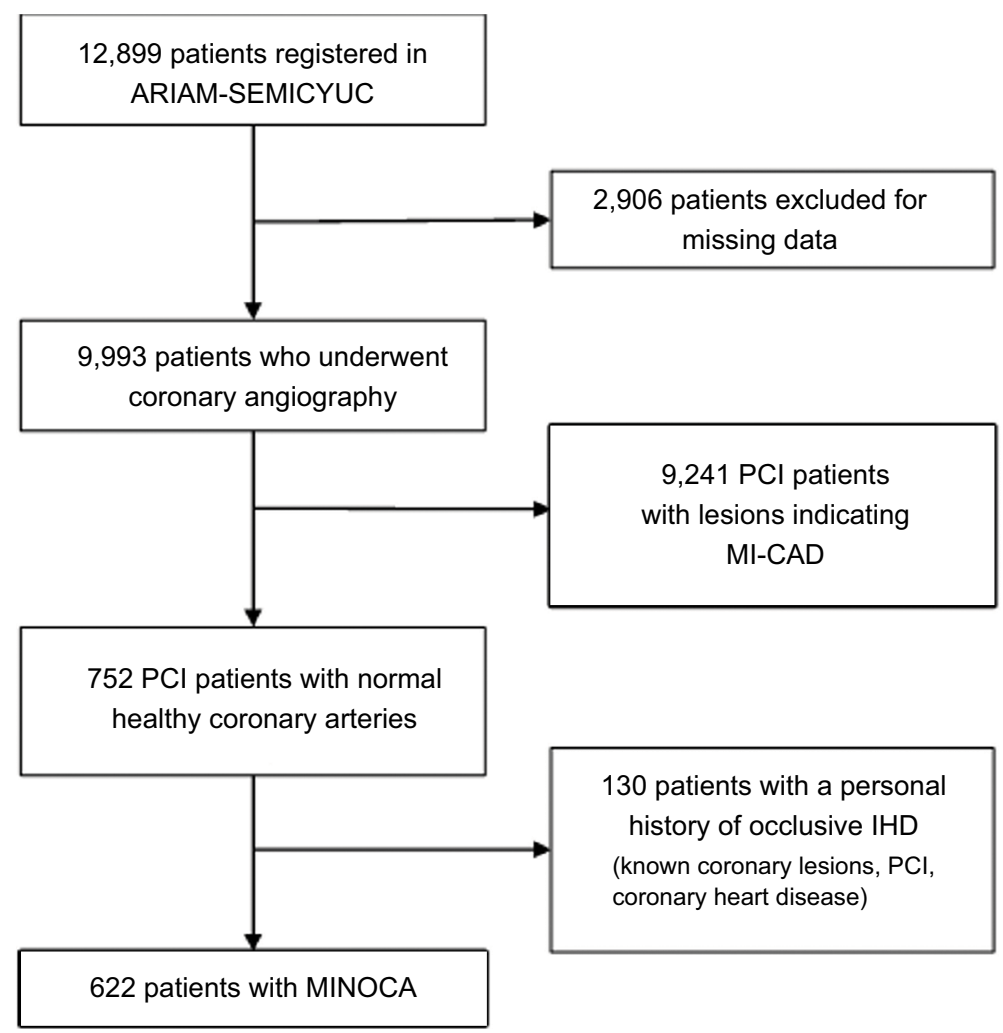

Figure I Flowchart of the selection process.

Abbreviations: AMI, acute myocardial infarction; ARIAM, Analysis of Delay in AMI; IHD, ischemic heart disease; MI-CAD, myocardial infarction with coronary artery disease; MINOCA, myocardial infarction with nonobstructive coronary arteries; PCl, percutaneous coronary intervention; SEMICYUC, Spanish Society of Intensive Care Medicine and Coronary Unit. 
MI-CAD and 752 as MINOCA. In this group, we excluded 130 patients who had a history of occlusive ischemic heart disease. The MINOCA group thus comprised 622 patients (Figure 1).

The characteristics of the study patients and their baseline characteristics are summarized in Table 1. Patients from the MINOCA group were younger, had a higher rate of female gender, and had less cardiovascular risk factors than patients from the MI-CAD group. In addition, cardiovascular drugs were administered more frequently to patients from the MI-CAD group.
At baseline, all patients underwent a hemodynamic workup and electrocardiogram (ECG) and were classified according to the Killip class. ${ }^{16}$ Risk was assessed using the Global Registry of Acute Coronary Events (GRACE) and thrombolysis In myocardial infarction (TIMI) scores, as summarized in Table 2. ${ }^{17,18}$ At the time of admission, the MINOCA group had less severe changes in the ECG and lower values in the Killip class, as well as in the TIMI and GRACE scores, than patients with MI-CAD.

Table I Demographic and baseline variables

\begin{tabular}{|c|c|c|c|}
\hline Variables & $\begin{array}{l}\text { MI-CAD (N=9,24I) } \\
N(\%)\end{array}$ & $\begin{array}{l}\text { MINOCA }(\mathrm{N}=622) \\
\text { N (\%) }\end{array}$ & $P$-value \\
\hline Gender, female & $2,019(21.9)$ & $305(49.0)$ & $<0.001$ \\
\hline Age (years), median (IQR) & $65(55-75)$ & $63(50-74)$ & $<0.001$ \\
\hline BMI, median (IQR) & $27.3(25.0-29.9)$ & $27.0(24.5-29.4)$ & 0.32 \\
\hline Ex-smoker & $2,207(23.9)$ & $87(14)$ & $<0.001$ \\
\hline Current smoker & $3,360(36.4)$ & $169(27.1)$ & $<0.001$ \\
\hline Nonsmoker & $2,839(30.7)$ & $294(47.3)$ & $<0.001$ \\
\hline Hypertension & $5,443(58.9)$ & $326(52.4)$ & 0.001 \\
\hline Known CAD & I,396 (I5.I) & $0(0.0)$ & $<0.001$ \\
\hline Family history of ischemic heart disease & I,088 (II.7) & $71(11.4)$ & 0.594 \\
\hline Dyslipidemia & $4,722(5 I .1)$ & $275(44.2)$ & $<0.001$ \\
\hline Diabetes mellitus & $2,590(28.0)$ & $116(18.7)$ & $<0.001$ \\
\hline Consumption of cocaine & $96(1.0)$ & II (I.8) & 0.069 \\
\hline Previous angina & $\mathrm{I}, 695(18.3)$ & $89(14.3)$ & 0.012 \\
\hline Previous AMI & $1,554(16.8)$ & $29(4.7)$ & $<0.001$ \\
\hline Stroke & $514(5.5)$ & $25(4.0)$ & 0.1 \\
\hline Peripheral artery disease & $593(6.4)$ & $14(2.2)$ & $<0.001$ \\
\hline Heart failure & $280(3.0)$ & $19(3.1)$ & 0.965 \\
\hline COPD & $701(7.6)$ & $39(6.3)$ & 0.227 \\
\hline Chronic kidney disease & $445(4.8)$ & $19(3.1)$ & 0.046 \\
\hline \multicolumn{4}{|l|}{ Treatment before admission } \\
\hline Acetylsalicylic acid & $2,396(25.9)$ & $88(14.2)$ & $<0.001$ \\
\hline \multicolumn{4}{|l|}{ Other antiplatelet agents } \\
\hline None & $8,318(90.0)$ & $600(96.5)$ & $<0.001$ \\
\hline Clopidogrel & $784(8.5)$ & $21(3.4)$ & $<0.001$ \\
\hline Prasugrel & $35(0.4)$ & $0(0.0)$ & 0.168 \\
\hline Ticagrelor & $21(0.2)$ & $0(0.0)$ & 0.64 \\
\hline Others & $71(0.8)$ & $\mathrm{I}(0.1)$ & 0.089 \\
\hline Nitrates & $656(7.1)$ & $25(4.0)$ & 0.003 \\
\hline Beta-blockers & $1,743(18.9)$ & $91(14.6)$ & 0.008 \\
\hline Calcium channel antagonists & $\mathrm{I}, 168(12.7)$ & $59(9.5)$ & 0.02 \\
\hline ACEI/ARA-II & $3,318(35.9)$ & $200(32.1)$ & 0.054 \\
\hline Statins/other lipid-lowering drugs & $3,294(35.6)$ & $176(28.3)$ & $<0.001$ \\
\hline Oral anticoagulants & $379(4.1)$ & $38(6.1)$ & 0.017 \\
\hline
\end{tabular}

Abbreviations: ACEl, angiotensin-converting enzyme inhibitors; AMI, acute myocardial infarction; ARA-II, angiotensin receptor antagonists-II; BMI, body mass index; CAD, coronary artery disease; MI-CAD, myocardial infarction with CAD; MINOCA, myocardial infarction with nonobstructive coronary arteries. 
Table 2 Assessment on admission

\begin{tabular}{|c|c|c|c|}
\hline Variables & $\begin{array}{l}\text { MI-CAD (N=9,24I) } \\
N(\%)\end{array}$ & $\begin{array}{l}\text { MINOCA }(\mathrm{N}=622) \\
\mathrm{N}(\%)\end{array}$ & $P$-value \\
\hline \multicolumn{4}{|l|}{ ECG at admission } \\
\hline ECG normal & $462(5.0)$ & $67(10.8)$ & $<0.001$ \\
\hline New LBBB & $73(0.8)$ & $10(1.6)$ & 0.018 \\
\hline ST segment depression $<0.5 \mathrm{~mm}$ & $408(4.4)$ & $37(6.0)$ & 0.03 \\
\hline ST depression $\geq 0.5 \mathrm{~mm}$ & $\mathrm{I}, 057(\mathrm{II} .4)$ & $72(11.6)$ & 0.513 \\
\hline ST elevation $<2 \mathrm{~mm}$ & $924(10.0)$ & $76(12.2)$ & 0.019 \\
\hline ST elevation $\geq 2 \mathrm{~mm}$ & $4,194(45.4)$ & $119(19.1)$ & $<0.001$ \\
\hline Transient ST elevation ( $<20$ minutes) & $339(3.7)$ & $37(6.0)$ & 0.001 \\
\hline T wave inversion & $807(8.7)$ & $112(18.0)$ & $<0.001$ \\
\hline LMCA/multivessel pattern & $150(1.6)$ & $2(0.3)$ & 0.009 \\
\hline Others/unknown & $827(9.0)$ & $90(14.4)$ & $<0.001$ \\
\hline \multicolumn{4}{|l|}{ Hemodynamic values } \\
\hline Killip class I & $7,280(78.8)$ & $516(83.0)$ & 0.014 \\
\hline Killip class II & $1,218(13.2)$ & $70(11.2)$ & 0.166 \\
\hline Killip class III & $479(5.2)$ & $29(4.7)$ & 0.567 \\
\hline Killip class IV & $259(2.8)$ & $7(1.1)$ & 0.012 \\
\hline Systolic pressure $(\mathrm{mmHg})$, median (IQR) & $135(\mid 18-153)$ & $134(120-150)$ & 0.934 \\
\hline Diastolic pressure (mmHg), median (IQR) & $75(65.5-88)$ & $75(65-87)$ & 0.141 \\
\hline Heart rate (bpm), median (IQR) & $75(65-89)$ & $78(67-90)$ & $<0.001$ \\
\hline \multicolumn{4}{|l|}{ Laboratory values } \\
\hline Creatinine (mg/dL), median (IQR) & $0.93(0.8-1.1)$ & $0.90(0.7-1.1)$ & $<0.001$ \\
\hline Platelet count $\left(\times 10^{3} / \mathrm{mL}\right)$, median $(\mathrm{IQR})$ & $189(155-228)$ & $199(169-237)$ & 0.005 \\
\hline Total cholesterol (mg/dL), median (IQR) & 168 (139-199) & $170.5(\mid 40.5-199.5)$ & 0.611 \\
\hline HDL cholesterol (mg/dL), median (IQR) & $39(33-47)$ & $45(36-54)$ & $<0.001$ \\
\hline Triglycerides (mg/dL), median (IQR) & $119(89-163)$ & $111(82.5-154)$ & 0.012 \\
\hline Hematocrit (\%), median (IQR) & $42(38.1-45)$ & $41.2(37.8-43.4)$ & 0.024 \\
\hline Hemoglobin (g/L), median (IQR) & $14(12.9-15.2)$ & $13.9(\mid 2.7-14.8)$ & 0.086 \\
\hline \multicolumn{4}{|l|}{ Evaluation of risk } \\
\hline TIMI score, median (IQR) & $3(2-4)$ & $2(I-3)$ & $<0.001$ \\
\hline GRACE score, median (IQR) & $142(120-168)$ & $126.5(100.5-153)$ & $<0.001$ \\
\hline
\end{tabular}

Abbreviations: ECG, electrocardiogram; GRACE, Global Registry of Acute Coronary Events; HDL, high-density lipoprotein; LBBB, left bundle branch block; LMCA, left mean coronary artery; MI-CAD, myocardial infarction with coronary artery disease; MINOCA, myocardial infarction with nonobstructive coronary arteries; TIMI, thrombolysis in myocardial infarction.

Table 3 summarizes the occurrence of complications during ICU/CCU admission and at 30 days. Cardiovascular complications were more frequently present in the MICAD group during ICU/CCU stay, with special relevance of acute kidney failure ( $4 \%$ vs $1.3 \%, P<0.001$ ), cardiogenic shock $(5.5 \%$ vs $2.2 \%, P<0.001)$, and death $(2.8 \%$ vs $1.1 \%$, $P=0.045)$. Compared with the MI-CAD group, fewer patients in the MINOCA group had higher levels (more than nine times the reference limit used by each center) of serum markers of myocardial damage (Figure 2), indicating a more extensive myocardial lesion.

At 30 days of follow-up, more complications related to cardiovascular problems were recorded in the MI-CAD group. The NYHA functional class was better in the MINOCA group.

Survival rate at 30 days was higher for the MI-CAD group, without statistical significance $(P=0.632)$. The $P$-value of Wilcoxon test for the survival curves was 0.013 (Figure 3 ).

\section{Creation of the MINOCA predictive score}

A binomial logistic regression model was created using the stepwise method so that only significant variables were included in the final models. The dependent variable was the MINOCA/MI-CAD group; the independent variables were all those that were statistically significant in the bivariate analysis. 
Table 3 Outcomes

\begin{tabular}{|l|l|l|l|}
\hline Complications & $\begin{array}{l}\text { MI-CAD } \\
\mathbf{( N = 9 , 2 4 I )} \\
\mathbf{N}(\%)\end{array}$ & $\begin{array}{l}\text { MINOCA } \\
\mathbf{( N = 6 2 2 )} \\
\mathbf{N}(\%)\end{array}$ & P-value \\
\hline During ICU/CCU admission & & & \\
\hline $\begin{array}{l}\text { Hemorrhage requiring } \\
\text { transfusion or with } \\
\text { hemodynamic instability }\end{array}$ & $55(0.6)$ & $\mathrm{I}(0.2)$ & $0.26 \mathrm{I}$ \\
\hline Stroke & & & \\
\hline Hemorrhagic & $9(0 . \mathrm{I})$ & $0(0.0)$ & $\mathrm{I}$ \\
\hline Ischemic & $38(0.4)$ & $0(0.0)$ & 0.169 \\
\hline Acute kidney failure & $367(4.0)$ & $8(1.3)$ & $0.00 \mathrm{I}$ \\
\hline Reinfarction & $\mathrm{I38}(\mathrm{I} .5)$ & $\mathrm{I}(0.2)$ & 0.003 \\
\hline Post-AMI angina & $2 \mathrm{I} 2(2.3)$ & $4(0.6)$ & 0.005 \\
\hline Cardiac tamponade & $47(0.5)$ & $\mathrm{I}(0.2)$ & 0.368 \\
\hline Pulmonary embolism & $4(0 . \mathrm{I})$ & $3(0.5)$ & 0.007 \\
\hline Right heart failure & $72(0.8)$ & $\mathrm{I}(0.2)$ & $0.13 \mathrm{I}$ \\
\hline Cardiogenic shock & $509(5.5)$ & $\mathrm{I} 4(2.2)$ & $<0.00 \mathrm{I}$ \\
\hline Death & $263(2.8)$ & $7(\mathrm{I} . \mathrm{I})$ & 0.045 \\
\hline At 30 days & & & \\
\hline NYHA functional class & & & \\
\hline NYHA I & $3,502(37.9)$ & $276(44.4)$ & 0.044 \\
\hline NYHA II & $\mathrm{I}, 435(\mathrm{I} 5.5)$ & $8 \mathrm{I}(\mathrm{I3.0)}$ & 0.008 \\
\hline NYHA III & $367(4.0)$ & $32(5 . \mathrm{I})$ & 0.323 \\
\hline NYHA IV & $95(\mathrm{I} .0)$ & $6(\mathrm{I} .0)$ & 0.724 \\
\hline Need for coronary angiography & $247(2.7)$ & $5(0.8)$ & $0.00 \mathrm{I}$ \\
\hline Need for PCI & $\mathrm{I} 36(\mathrm{I} .5)$ & $0(0.0)$ & $<0.00 \mathrm{I}$ \\
\hline Readmission & $468(5 . \mathrm{I})$ & $27(4.4)$ & 0.256 \\
\hline New AMI & $64(0.7)$ & $0(0.0)$ & $0.02 \mathrm{I}$ \\
\hline CPR & $\mathrm{II}(0 . \mathrm{I})$ & $0(0.0)$ & $\mathrm{I}$ \\
\hline Death & $69(0.8)$ & $3(0.5)$ & 0.632 \\
\hline Ab & & \\
\hline
\end{tabular}

Abbreviations: AMI, acute myocardial infarction; $\mathrm{CCU}$, coronary care unit; CPR, cardiopulmonary resuscitation; ICU, intensive care unit; MI-CAD, myocardial infarction with coronary artery disease; MINOCA, myocardial infarction with nonobstructive coronary arteries; NYHA, New York Heart Association; PCI, percutaneous coronary intervention.
MINOCA was predicted by calculating the OR with its 95\% CI and $P$-value. The results are presented in Table 4, showing that the variables were used to construct the nomogram.

We found that the typical MINOCA patient was a nonsmoking woman aged $<50$ years with $\mathrm{cTn}<9$ times the limit of the normal range and no personal history of arterial hypertension, diabetes mellitus, or AMI. The discriminative power was 0.756 , which is close to unity and therefore confirms that the model can detect patients with MINOCA. Furthermore, the $P$-value for the Hosmer-Lemeshow test was $>0.05$, thus indicating a good predictive adjustment of the regression model.

The MINOCA predictive score was created using the previous regression model, where the coefficients calculated in the final model were used to construct the predictive model in the form of a nomogram, that is, a graphical representation of the relative impact of each prognostic factor within the global model (Figure 3).

The predictive capacity of the final model was evaluated using calibration and the discriminative power that enabled the internal validation of the final model. The model was validated by means of the following tasks:

- A prognostic index (PI) was created using the following model: $\mathrm{IP}=\alpha \mathrm{x}+\alpha \mathrm{x} 1 \times 1+\ldots+\alpha \mathrm{kxk}$, that is, we kept the variable resulting from the model in our database. The sample was divided into risk groups by applying the cutoff points to the PI based on specific percentiles of patients with an event.

- The KM curves were constructed for the groups (observed survival). These were compared with those predicted for the model for the mean values of the PI in the groups.

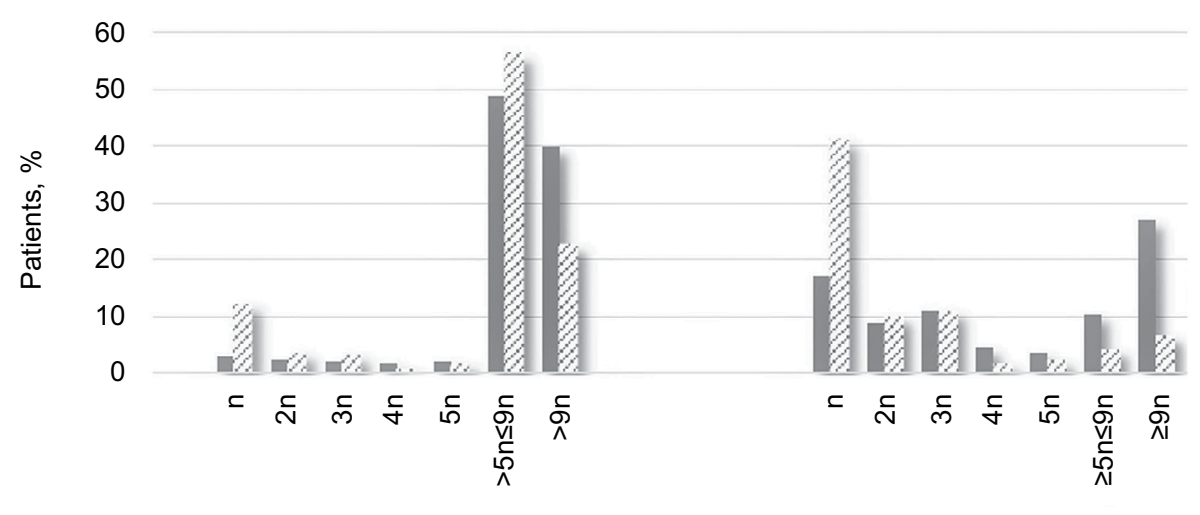

Peak levels of troponin

Peak levels of creatine kinase

MI-CAD $\nLeftarrow$ MINOCA

Figure 2 Plasma levels of markers of myocardial damage.

Notes: The proportion of patients with different peaks of the level of markers of myocardial injury is shown. $\mathrm{n}$ denotes the limit of the laboratory normal range.

Abbreviations: MI-CAD, myocardial infarction with coronary artery disease; MINOCA, myocardial infarction with nonobstructive coronary arteries. 


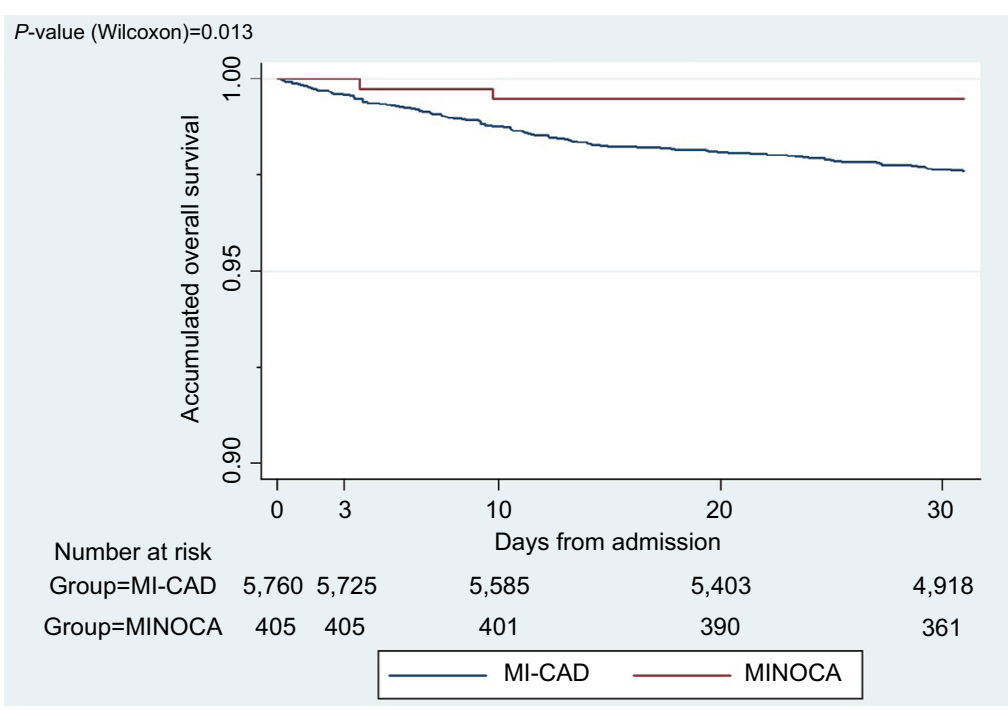

Figure 3 Mortality at 30 days of follow-up.

Note: Patients with follow-up completed at 30 days are included in the figure.

Abbreviations: MI-CAD, myocardial infarction with coronary artery disease; MINOCA, myocardial infarction with nonobstructive coronary arteries.

Table 4 Statistically significant variables

\begin{tabular}{|l|l|l|l|l|}
\hline Variables & OR & \multirow{2}{*}{-value } & \multicolumn{2}{|l|}{$\mathbf{9 5} \mathbf{C l}$} \\
\cline { 3 - 5 } & & & Lower & Upper \\
\hline Gender, female & 3.52 & $<0.00 \mathrm{I}$ & 2.58 & $4.8 \mathrm{I}$ \\
\hline Age $>50$ years & 0.37 & $<0.00 \mathrm{I}$ & 0.25 & 0.53 \\
\hline Troponin $>9$-fold & 0.53 & $<0.00 \mathrm{I}$ & 0.38 & 0.74 \\
\hline Smoker & 0.62 & $<0.00 \mathrm{I}$ & $0.5 \mathrm{I}$ & 0.75 \\
\hline Hypertension & 0.63 & 0.004 & 0.46 & 0.86 \\
\hline Diabetes mellitus & 0.59 & 0.012 & 0.4 & 0.89 \\
\hline Previous infarction & 0.4 & 0.009 & 0.2 & 0.79 \\
\hline P-value (Hosmer-Lemeshow) & & 0.157 & \\
\hline C-statistic & & 0.756 & \\
\hline
\end{tabular}

Figure 4 shows the probability that a patient with AMI has MINOCA at admission. The score value was obtained by summing the scores for the variables that comprised the nomogram. The values ranged from 0 to 48 . The maximum value corresponded to a $40 \%$ probability of MINOCA.

\section{Discussion}

The ARIAM project has become one of the most important registries of ACS in the world with data from more than 160,000 patients throughout Spain and Andorra. ${ }^{19-22}$

The data obtained show that patients with MINOCA account for $6 \%$ of all cases of AMI diagnosed in Spain. The main characteristics of these patients are as follows: younger age than patients with obstructive coronary disease with no differences in distribution by gender; fewer risk factors for cardiovascular disease or known cardiovascular conditions before admission; less severe disease during admission and, therefore, a lower rate of complications, including death.

Although these characteristics had already been reported elsewhere, they had never been reviewed in Spain. As our findings are consistent with previously published data, they can be generalized to the whole of Spain., ${ }^{4,5,9-11,23-25}$

As shown in Figure 5, the rate of MINOCA was about $6 \%$ in most reported series of patients in agreement with our results. The high incidence of coronary artery disease throughout the world means that the number of patients with MINOCA is also high. If we take the available data from the hospital morbidity survey of the Spanish National Statistics Institute (ie, 54,090 discharges with a diagnosis of AMI), and given a prevalence of around $6 \%$ of patients with AMI, then approximately 3,400 patients had MINOCA in Spain in 2014. ${ }^{26}$

Although no registry data are available, medication is usually withdrawn from MINOCA patients before the end of the workup, thus underestimating the importance of the process without reaching a definitive diagnosis, as these patients are not thought to be at risk of death. This entails consequences for the patients since their prognosis is not that of the general population. ${ }^{27}$ Unlike this assumption for patients with MINOCA, morbidity and mortality are increased in the short, medium, and long terms, with the onset of new episodes of acute ischemic heart disease and death. In the ACUITY study, the adjusted risk of death at 1 


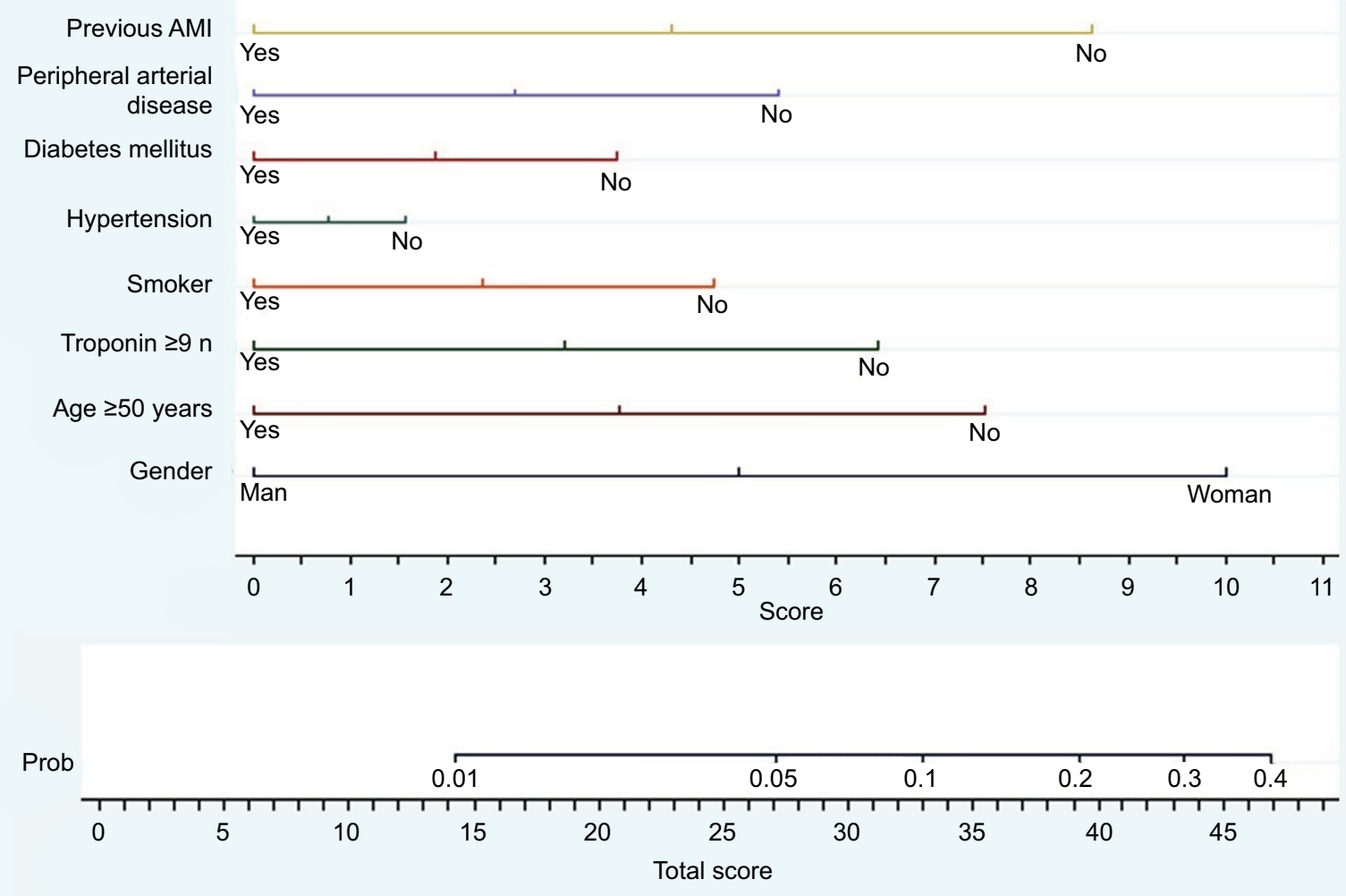

Figure 4 Nomogram for predicting MINOCA.

Note: Impact of each prognostic factor within the global model. $\mathrm{n}$ denotes the limit of the laboratory normal range.

Abbreviations: AMI, acute myocardial infarction; MINOCA, myocardial infarction with nonobstructive coronary arteries; Prob, probability.

year was $5.2 \%$, which the researchers attributed to the poorer prognosis of these patients and the possible lack of assessment and treatment of the origin of the increase in AMI after coronary angiography. ${ }^{28}$ Therefore, some of the patients did not receive appropriate treatment with the possibility that the disease could progress or the event could recur.

Patients with MINOCA presented an event that led to myocardial ischemia with necrosis of myocardium. The present tool enables clinicians to suspect the presence of nonobstructive disease and act earlier to schedule new diagnostic tests and to prescribe appropriate therapy.

In 2000, Roe et al ${ }^{24}$ published the results of a study where they attempted to differentiate between patients with ACS without ST segment elevation who had obstructive disease and those who did not. The authors aimed to be able to distinguish between patients on administering treatment with anti-IIb/IIIa antiplatelet therapy. Their results show that patients with nonobstructive disease share characteristics with the MINOCA patients in our study. The authors designed a predictive score based on the patients' baseline characteristics with a C-statistic value of 0.827 , indicating that the model can reliably predict the presence of coronary artery disease without significant obstruction. Furthermore, when the predictive model was applied to the patients in the GUSTO-IIb trial, the C-statistic was 0.796 , indicating excellent discrimination of the model when applied to a different population. ${ }^{29}$ In contrast with this algorithm, our score is aimed at patients with a diagnosis of AMI, and it is also easier to perform, since it is done with values that are easily obtained at the patient's admision.

MINOCA is currently diagnosed based on coronary angiography to rule out coronary obstruction. In the case of patients who fulfill the diagnostic criteria for MINOCA, every attempt should be made to determine the etiology to manage the condition appropriately, since the origin may not even be cardiac, thus necessitating specific assessment and therapy. ${ }^{29}$ In this way, the application of a score elaborated with immediate clinical data could allow clinicians to choose patients for the accomplishment of minimally invasive diagnostic tests, which allow them to exclude coronary disease. ${ }^{30}$ Recent reports have demonstrated that computed tomography (CT) coronary angiography can target planned interventions in patients with angina, including coronary angiography, 
Table 5 Prevalence of MINOCA in most relevant studies

\begin{tabular}{|c|c|}
\hline $\begin{array}{l}\text { Authors of the studies / year } \\
\text { of publication }\end{array}$ & Proportion $(95 \% \mathrm{Cl})$ \\
\hline Larsen et $\mathrm{al}^{32} / 2013$ & $0.04(0.03-0.04)$ \\
\hline Collste et $\mathrm{al}^{31} / 2013$ & $0.06(0.06-0.07)$ \\
\hline Sun et $\mathrm{al}^{33} / 2012$ & $0.02(0.00-0.03)$ \\
\hline Rhew et al ${ }^{34} / 2012$ & $0.08(0.07-0.10)$ \\
\hline Hamdan et a $\left.\right|^{35} / 2012$ & $0.09(0.04-0.14)$ \\
\hline Aldrovandi et $\mathrm{al}^{36} / 2012$ & $0.04(0.03-0.04)$ \\
\hline Agewall et al / 2012 & $0.07(0.03-0.1 \mathrm{I})$ \\
\hline Tritto et $\mathrm{al}^{37} / 20 \mathrm{II}$ & $0.05(0.04-0.06)$ \\
\hline Leurent et al ${ }^{38} / 2011$ & $0.13(0.11-0.16)$ \\
\hline Kang et $\mathrm{al}^{39} / 201 \mathrm{I}$ & $0.04(0.04-0.12)$ \\
\hline Uchida et $\mathrm{al}^{40 / 2010}$ & $0.08(0.04-0.12)$ \\
\hline Frycz-Kurek et al ${ }^{41} / 2010$ & $0.03(0.03-0.03)$ \\
\hline Gehrie et $\mathrm{a}^{42} / 2009$ & $0.10(0.07-0.13)$ \\
\hline Baccouche et $\mathrm{al}^{43} / 2009$ & $0.14(0.12-0.16)$ \\
\hline Ong et $\mathrm{al}^{44} / 2008$ & $0.10(0.07-0.13)$ \\
\hline Ahmar et al ${ }^{45} / 2008$ & $0.06(0.05-0.07)$ \\
\hline Larson et $\mathrm{al}^{46} / 2007$ & $0.04(0.03-0.05)$ \\
\hline Widimsky et al ${ }^{47} / 2006$ & $0.03(0.02-0.04)$ \\
\hline Strunk et al ${ }^{48} / 2006$ & $0.08(0.05-0.10)$ \\
\hline Patel et al" / 2006 & $0.09(0.08-0.09)$ \\
\hline Larsen et $\mathrm{al}^{49} / 2005$ & $0.07(0.07-0.08)$ \\
\hline Germing et $\mathrm{al}^{50} / 2005$ & $0.06(0.04-0.08)$ \\
\hline Hung et $\mathrm{a}^{51} / 2003$ & $0.10(0.06-0.14)$ \\
\hline Gehani et al $\left.\right|^{52} / 2001$ & $0.05(0.04-0.06)$ \\
\hline Hochman et al $\left.\right|^{53} / 1999$ & $0.07(0.06-0.07)$ \\
\hline Zimmerman et al ${ }^{54} / 1995$ & $0.04(0.04-0.05)$ \\
\hline Sharifi et al $\left.\right|^{55} / 1995$ & $0.01(0.00-0.02$ \\
\hline Overall & $0.06(0.05-0.07)$ \\
\hline Ballesteros et al & $0.06(0.06-0.07)$ \\
\hline
\end{tabular}

Notes: Prevalence of MINOCA in various studies (overall 6\%, in red text; systematic review from Pasupathy et $\mathrm{al}^{4}$ ) compared with the present study (blue text), showing $6.3 \%$ of patients with MINOCA diagnosis.

Abbreviations: MINOCA, myocardial infarction with nonobstructive coronary arteries.

improving outcome. ${ }^{56,57}$ It is needed to carry out a study aimed to show a reduction in coronary angiography of patients with suspected MINOCA through less invasive procedure such as CT coronary angiography or other imaging tests.

\section{Limitations of the study}

The main limitation of our study is the lack of alternative diagnosis for MINOCA patients. Due to the short-term follow-up of the ARIAM registry, additional studies and definitive diagnosis are not known for these patients.

Another limitation of our score is the relatively low predictive value $(40 \%$ probability of MINOCA with the highest score), although other widely used scores show similar values. The TIMI risk score for unstable angina and non-ST segment elevation showed a probability of $40.9 \%$ for all-cause mortality, MI, and severe recurrent ischemia prompting urgent revascularization through 14 days for the maximum score value. ${ }^{58}$ The risk prediction tool from the GRACE study showed C-statistics of 0.81 for predicting death and 0.73 for death or MI from admission to 6 months after discharge, which is similar to our results. ${ }^{59}$

\section{Conclusion}

In our registry, patients with MINOCA present characteristics which differentiate them early from those with MI-CAD. The diagnosis of MINOCA does not suppose the exclusion of an unfavorable outcome or future complications.

The score we present can accurately predict the diagnosis of MINOCA, encouraging clinicians to perform alternative tests for the correct diagnosis of these patients and allowing a correct treatment. This score is determined easily and quickly, not requiring tests in addition to those performed in the current ACS protocols. Further trials to establish definitive diagnosis for these patients are needed.

\section{Acknowledgment}

The present study was funded in part by a grant from Fundación Universidad Alfonso X El Sabio-Santander (FUAX). The ARIAM-SEMICYUC registry is fully funded by SEMICYUC. The authors would also like to acknowledge the ARIAM-SEMICYUC Group.

\section{Disclosure}

The authors report no conflicts of interest in this work.

\section{References}

1. Lloyd-Jones D, Adams RJ, Brown TM. American Heart Association Statistics Committee and Stroke Statistics Subcommittee. Executive summary: heart disease and stroke statistics-2010 update: a report from the American Heart Association. Circulation. 2010;121(7):948-954.

2. Nichols M, Townsend N, Scarborough P, Rayner M. Cardiovascular disease in Europe: epidemiological update. Eur Heart J. 2013;34(39): 3028-3034.

3. Ibanez B, James S, Agewall S. ESC Scientific Document Group. 2017 ESC Guidelines for the management of acute myocardial infarction in patients presenting with ST-segment elevation: The Task Force for the management of acute myocardial infarction in patients presenting with ST-segment elevation of the European Society of Cardiology (ESC). Eur Heart J. 2017;39(2):119-177.

4. Pasupathy S, Air T, Dreyer RP, Tavella R, Beltrame JF. Systematic review of patients presenting with suspected myocardial infarction and nonobstructive coronary arteries. Circulation. 2015;131(10):861-870.

5. Pizzi C, Xhyheri B, Costa GM, et al. Nonobstructive Versus Obstructive Coronary Artery Disease in Acute Coronary Syndrome: A Meta- Analysis. J Am Heart Assoc. 2016;5(12):e004185.

6. Niccoli G, Scalone G, Crea F. Acute myocardial infarction with no obstructive coronary atherosclerosis: mechanisms and management. Eur Heart J. 2015;36(8):475-481.

7. Berger JS, Elliott L, Gallup D, et al. Sex differences in mortality following acute coronary syndromes. JAMA. 2009;302(8):874-882. 
8. Shaw LJ, Shaw RE, Merz CN. American College of Cardiology-National Cardiovascular Data Registry Investigators. Impact of ethnicity and gender differences on angiographic coronary artery disease prevalence and in-hospital mortality in the American College of Cardiology-National Cardiovascular Data Registry. Circulation. 2008;117(14):1787-1801.

9. Agewall S, Daniel M, Eurenius L, et al. Risk factors for myocardial infarction with normal coronary arteries and myocarditis compared with myocardial infarction with coronary artery stenosis. Angiology. 2012;63(7): 500-503.

10. Ohlow MA, Wong V, Brunelli M, et al. Acute coronary syndrome without critical epicardial coronary disease: prevalence, characteristics, and outcome. Am J Emerg Med. 2015;33(2):150-154.

11. Patel MR, Chen AY, Peterson ED, et al. Prevalence, predictors, and outcomes of patients with non-ST-segment elevation myocardial infarction and insignificant coronary artery disease: results from the Can Rapid risk stratification of Unstable angina patients Suppress ADverse outcomes with Early implementation of the ACC/AHA Guidelines (CRUSADE) initiative. Am Heart J. 2006;152(4):641-647.

12. Spanish Society of Intensive Medicine and Coronary Units [Sociedad Española de Medicina Intensiva y Unidades Coronarias (SEMICYUC)] [homepage on the Internet]. Available from: http://www.semicyuc.org/ temas/investigacion/registros/ariam. Accessed on June 14, 2018.

13. Agewall S, Beltrame JF, Reynolds H, et al. On behalf of the WG on Cardiovascular Pharmacotherapy. ESC working group position paper on myocardial infarction with non-obstructive coronary arteries. Eur Heart J. 2017;38(3):143-153.

14. Flynn MR, Barrett C, Cosío FG, et al. The Cardiology Audit and Registration Data Standards (CARDS), European data standards for clinical cardiology practice. Eur Heart J. 2005;26(3):308-313.

15. Analysis of the Delay in Acute Myocardial Infarction [Análisis del Retraso en el infarto Agudo de Miocardio (ARIAM)] [homepage on the Internet]. Available from: https://ariam.investigacion-intensivos.org/ login.php. Accessed on May 02, 2016.

16. Killip T, Kimball JT. Treatment of myocardial infarction in a coronary care unit. A two year experience with 250 patients. Am J Cardiol. 1967;20(4):457-464.

17. Rationale and design of the GRACE (Global Registry of Acute Coronary Events) Project: a multinational registry of patients hospitalized with acute coronary syndromes. Am Heart J. 2001; 141(2):190-9.

18. Morrow DA, Antman EM, Snapinn SM, Mccabe CH, Theroux P, Braunwald E. An integrated clinical approach to predicting the benefit of tirofiban in non-ST elevation acute coronary syndromes. Application of the TIMI Risk Score for UA/NSTEMI in PRISM-PLUS. Eur Heart J. 2002;23(3):223-229.

19. Huynh T, Cox JL, Massel D, et al. Predictors of intracranial hemorrhage with fibrinolytic therapy in unselected community patients: a report from the FASTRAK II project. Am Heart J. 2004;148(1):86-91.

20. Gottlieb S. Mortality trends in men and women with acute myocardial infarction in coronary care units in Israel. A comparison between 1981-1983 and 1992-1994. Eur Heart J. 2000;21(4):284-295.

21. Rustige J, Schiele R, Burczyk U, et al. The 60 minutes myocardial infarction project. Treatment and clinical outcome of patients with acute myocardial infarction in Germany. Eur Heart J. 1997;18(9): 1438-1446.

22. Tunstall-Pedoe H, Kuulasmaa K, Mähönen M, Tolonen H, Ruokokoski E, Amouyel P. Contribution of trends in survival and coronary-event rates to changes in coronary heart disease mortality: 10-year results from 37 WHO MONICA Project populations. Lancet. 1999;353(9164): $1547-1557$

23. Platelet Glycoprotein IIb/IIIa in Unstable Angina: Receptor Suppression Using Integrilin Therapy (PURSUIT) Trial Investigators. Inhibition of platelet glycoprotein IIb/IIIa with eptifibatide in patients with acute coronary syndromes. $N$ Engl J Med. 1998;339:436-443.

24. Roe MT, Harrington RA, Prosper DM, et al. Clinical and therapeutic profile of patients presenting with acute coronary syndromes who do not have significant coronary artery disease. The Platelet Glycoprotein IIb/IIIa in Unstable Angina: Receptor Suppression Using Integrilin Therapy (PURSUIT) Trial Investigators. Circulation. 2000;102(10): $1101-1106$
25. Ferrer Gracia MC, Hernández-Antolín RA, Pérez-Vizcayno MJ, Conde Vela C, Alfonso Manterola F, Macaya Miguel C. Myocardial infarction with ST segment elevation and angiographically normal coronary arteries: epidemiology and mid-term follow-up. Med Clin. 2007;129(18):694-696.

26. National Institute of Statistics (Spain). Survey of hospital morbidity 2015. National results. Hospital admissions and according to main diagnosis. [Instituto Nacional de Estadística (INE). Encuesta de morbilidad hospitalaria 2015. Resultados nacionales. Altas hospitalarias y según diagnóstico principal]. [homepage on the Internet]. Available from: http://www.ine.es/jaxi/Datos.htm?path=/. Accessed on May 02, 2016.

27. Nordenskjöld AM, Baron T, Eggers KM, Jernberg T, Lindahl B. Predictors of adverse outcome in patients with myocardial infarction with non-obstructive coronary artery (MINOCA) disease. Int $J$ Cardiol. 2018;261:18-23.

28. Stone GW, Bertrand M, Colombo A, et al. Acute Catheterization and Urgent Intervention Triage strategY (ACUITY) trial: study design and rationale. Am Heart J. 2004;148(5):764-775.

29. Global Use of Strategies to Open Occluded Coronary Arteries (GUSTO) IIb Investigators. A comparison of recombinant hirudin with heparin for the treatment of acute coronary syndromes. N Engl J Med. 1996; 335(11): 775-82.

30. Pasupathy S, Tavella R, Beltrame JF. The What, When, Who, Why, How and Where of Myocardial Infarction With Non-Obstructive Coronary Arteries (MINOCA). Circ J. 2016;80(1):11-16.

31. Collste O, Sörensson P, Frick M, et al. Myocardial infarction with normal coronary arteries is common and associated with normal findings on cardiovascular magnetic resonance imaging: results from the Stockholm Myocardial Infarction with Normal Coronaries study. J Intern Med. 2013;273(2):189-196.

32. Larsen AI, Nilsen DW, Yu J et al. Long-term prognosis of patients presenting with ST-segment elevation myocardial infarction with no significant coronary artery disease from the HORIZONS-AMI trial. Am J Cardiol. 2013 Mar 1;111(5):643-648. Epub 2012 Dec 19.

33. Sun WX, Yan JH, Zhao XY, Ruan YP, Fan ZJ. [Risk factors and coronary angiography characteristics of female patients with acute coronary syndrome]. Zhonghua Xin Xue Guan Bing Za Zhi. 2012 Nov;40(11):897-901.

34. Rhew SH, Ahn Y, Kim MC et al. Is Myocardial Infarction in Patients without Significant Stenosis on a Coronary Angiogram as Benign as Believed? Chonnam Med J. 2012 Apr;48(1):39-46. Epub 2012 Apr 26.

35. Hamdan R, Frangieh A, Kadri Z et al. What do we know about myocardial infarction with normal coronary arteries? Gazzetta Medica Italiana Archivio per le Scienze Mediche. 2012;171:7-12

36. Aldrovandi A, Cademartiri F, Arduini D et al. Computed tomography coronary angiography in patients with acute myocardial infarction without significant coronary stenosis. Circulation. 2012 Dec 18;126(25):3000-7. Epub 2012 Nov 20.

37. Tritto I, Conti MG, Ambrosio G. Ischemia with normal coronary arteries: a puzzle and an opportunity. J Cardiovasc Med (Hagerstown). 2011 May;12(5):309-310.

38. Leurent G, Langella B, Fougerou C et al. Diagnostic contributions of cardiac magnetic resonance imaging in patients presenting with elevated troponin, acute chest pain syndrome and unobstructed coronary arteries. Arch Cardiovasc Dis. 2011 Mar;104(3):161-70. Epub 2011 Apr 2.

39. Kang WY, Jeong MH, Ahn YK et al. Are patients with angiographically near-normal coronary arteries who present as acute myocardial infarction actually safe? Int $J$ Cardiol. 2011 Jan 21;146(2):207-12. Epub 2009 Aug 7.

40. Uchida $Y$, Uchida $Y$, Sakurai $T$ et al. Fluffy luminal surface of the non-stenotic culprit coronary artery in patients with acute coronary syndrome: An angioscopic study. Circ J. 2010;74:2379-2385.

41. Frycz-Kurek AM, Gierlotka M, Gąsior M et al. Patients with no significant lesions in coronary arteries and ST-segment elevation myocardial infarction have worse outcome than patients with non-ST-segment elevation myocardial infarction: analysis from PL-ACS Registry. Kardiol Pol. 2010 Nov;68(11):1211-1217. 
42. Gehrie ER, Reynolds HR, Chen AY et al. Characterization and outcomes of women and men with non-ST-segment elevation myocardial infarction and nonobstructive coronary artery disease: results from the Can Rapid Risk Stratification of Unstable Angina Patients Suppress Adverse Outcomes with Early Implementation of the ACC/AHA Guidelines (CRUSADE) quality improvement initiative. Am Heart J. 2009 Oct;158(4):688-94.

43. Baccouche H, Mahrholdt H, Meinhardt G et al. Diagnostic synergy of non-invasive cardiovascular magnetic resonance and invasive endomyocardial biopsy in troponin-positive patients without coronary artery disease. Eur Heart J. 2009 Dec;30(23):2869-2879. Epub 2009 Aug 20.

44. Ong P, Athanasiadis A, Hill S, Vogelsberg H, Voehringer M, Sechtem U. Coronary artery spasm as a frequent cause of acute coronary syndrome: The CASPAR (Coronary Artery Spasm in Patients With Acute Coronary Syndrome) Study. J Am Coll Cardiol. 2008 Aug 12;52(7):523-7.

45. Ahmar W, Lefkovits J. Acute ST elevation myocardial infarction with angiographically normal coronary arteries: causes and outcomes. Int J Cardiol. 2008 Aug 1;128(1):131-3. Epub 2007 Aug 8.

46. Larson DM, Menssen KM, Sharkey SW et al. "False-positive" cardiac catheterization laboratory activation among patients with suspected STsegment elevation myocardial infarction. JAMA. 2007 Dec 19;298(23): 2754-60.

47. Widimsky P, Stellova B, Groch L, et PRAGUE Study Group Investigators. Prevalence of normal coronary angiography in the acute phase of suspected ST-elevation myocardial infarction: experience from the PRAGUE studies. Can J Cardiol. 2006 Nov;22(13):1147-1152.

48. Strunk B, Shaw RE, Bull S et al. High incidence of focal left ventricular wall motion abnormalities and normal coronary arteries in patients with myocardial infarctions presenting to a community hospital. J Invasive Cardiol. 2006 Aug;18(8):376-381.

49. Larsen AI, Galbraith PD, Ghali WA et APPROACH Investigators. Characteristics and outcomes of patients with acute myocardial infarction and angiographically normal coronary arteries. Am J Cardiol. 2005 Jan $15 ; 95(2): 261-3$
50. Germing A, Lindstaedt M, Ulrich S et al. Normal angiogram in acute coronary syndrome-preangiographic risk stratification, angiographic findings and follow-up. Int J Cardiol. 2005 Mar 10;99(1):19-23.

51. Hung MJ, Cherng WJ. Comparison of white blood cell counts in acute myocardial infarction patients with significant versus insignificant coronary artery disease. Am J Cardiol. 2003 Jun 1;91(11):1339-42.

52. Gehani AA, al-Mulla AW, Chaikhouni A et al. Myocardial infarction with normal coronary angiography compared with severe coronary artery disease without myocardial infarction: the crucial role of smoking. J Cardiovasc Risk. 2001 Feb;8(1):1-8.

53. Hochman JS, Tamis JE, Thompson TD et al. Sex, clinical presentation, and outcome in patients with acute coronary syndromes. Global Use of Strategies to Open Occluded Coronary Arteries in Acute Coronary Syndromes IIb Investigators. N Engl J Med. 1999 Jul 22;341(4):226-32.

54. Zimmerman FH, Cameron A, Fisher LD, Ng G. Myocardial infarction in young adults: angiographic characterization, risk factors and prognosis (Coronary Artery Surgery Study Registry). J Am Coll Cardiol. 1995 Sep;26(3):654-61.

55. Sharifi M, Frohlich TG, Silverman IM. Myocardial infarction with angiographically normal coronary arteries. Chest. 1995 Jan;107(1):36-40.

56. The SCOT-HEART investigators. CT coronary angiography in patients with suspected angina due to coronary heart disease (SCOTHEART): an open-label, parallel-group, multicentre trial. Lancet. 2015;385(9985):2383-2391.

57. The SCOT-HEART investigators. Coronary CT angiography and 5-year risk of myocardial infarction. N Engl J Med. 2018;379(10): 924-933.

58. Antman EM, Cohen M, Bernink PJ, et al. The TIMI risk score for unstable angina/non-ST elevation MI: A method for prognostication and therapeutic decision making. JAMA. 2000;284(7):835-842.

59. Kaa F, Dabbous OH, Goldberg RJ, et al. Prediction of risk of death and myocardial infarction in the six months after presentation with acute coronary syndrome: prospective multinational observational study (GRACE). BMJ. 2006;333:1091.
Vascular Health and Risk Management

\section{Publish your work in this journal}

Vascular Health and Risk Management is an international, peerreviewed journal of therapeutics and risk management, focusing on concise rapid reporting of clinical studies on the processes involved in the maintenance of vascular health; the monitoring, prevention and treatment of vascular disease and its sequelae; and the involvement of

\section{Dovepress}

metabolic disorders, particularly diabetes. This journal is indexed on PubMed Central and MedLine. The manuscript management system is completely online and includes a very quick and fair peer-review system, which is all easy to use. Visit http://www.dovepress.com/ testimonials.php to read real quotes from published authors. 